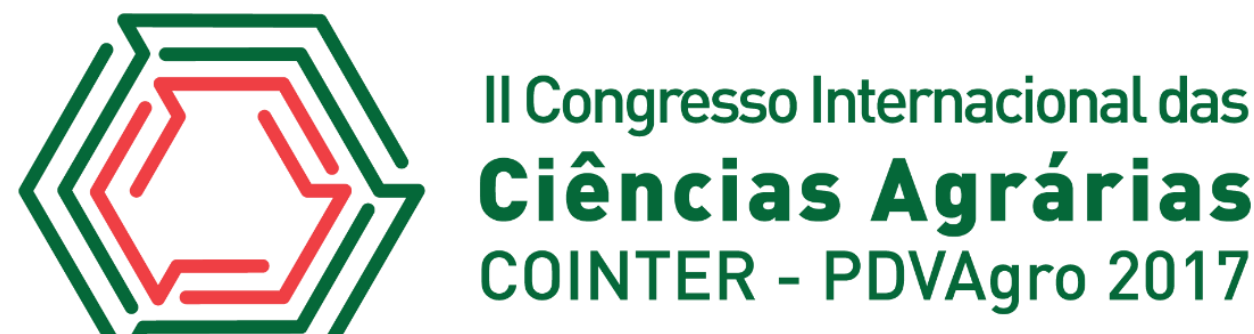

\section{BIOMETRIA, EMBEBIÇÃO E SUPERAÇÃO DE DORMÊNCIA DE SEMENTES DE} Bauhinia rufa.

Apresentação: Pôster

\author{
Alessandro da Costa Lima ${ }^{1}$; Gabriel Rodrigues da Costa ${ }^{2}$; Lucicleia Lima Silva ${ }^{3}$; Karla \\ Suanny Navarro ${ }^{4}$; Rafael Gomes Viana ${ }^{5}$
}

\section{Introdução}

Bauhinia rufa (Fabaceae) é uma planta conhecida popularmente como pata de vaca, sendo uma espécie lenhosa que pode apresentar hábito arbustivo e é comumente encontrada nas bordas das matas, apresentando distribuição que compreende boa parte do território brasileiro (Vaz e Tozzi, 2003). Esta espécie possui uso como planta medicinal e produz ésteres que proporcionam efeito negativo na sobrevivência de afídeos pragas em culturas (Bichuette et al., 1998). No entanto, a maior importância de uso se dá como componente de recuperação de áreas degradadas (RAD). Sementes de B. rufa podem ser misturadas a outras sementes e lançadas em áreas a serem recuperadas e dessa maneira revegetar áreas degradadas ou em processo de degradação. No entanto é frequente na RAD com $B$. rufa a dormência das sementes, acarretando, falhas de cobertura e desuniformidade de emergência. A falta de informações das fases de embebição de sementes e de dados biométricos da mesma também provocam dúvidas quanto a época de semeadura em relação a fase de necessidade hídrica e aos coeficientes biométricos das sementes. Devido a carência de informações das sementes de $B$. rufa e a importância de uso e aplicação, objetivou-se avaliar a biometria, embebição e superação de dormência de sementes de Bauhinia rufa.

\section{Fundamentação Teórica}

A influência do tamanho das sementes sobre a qualidade fisiológica tem sido pesquisada com certa intensidade em várias espécies (Alves et al., 2005). A caracterização física de sementes

\footnotetext{
${ }^{1}$ Graduando em Agronomia da Universidade Federal Rural da Amazônia, Campus Belém, E-mail: alelima.agro@gmail.com

2 Engenheiro Agrônomo, Universidade federal Rural da Amazônia, E-mail: gabrielrc18@gmail.com

${ }^{3}$ Graduanda em Agronomia da Universidade Federal Rural da Amazônia, Campus Belém, E-mail: lucicleialimasilva@hotmail.com

${ }^{4}$ Graduanda em Farmácia na Universidade da Amazônia, Campus Belém, E-mail: karlaenavarro@gmail.com

${ }^{5}$ Professor Doutor da Universidade Federal Rural da Amazônia, Instituto de Ciências Agrárias, rafael.gomes@ufra.edu.br
} 
pode fornecer subsídios importantes para a diferenciação de espécies do mesmo gênero, como também está relacionada a características da dispersão e do estabelecimento de plântulas (Cruz et al., 2001). Devido a características adaptativas e por ser planta nativa, B. rufa é uma espécie muito utilizada para estes fins em boa parte do território brasileiro. Seu principal meio de propagação é por sementes, e a sua síndrome de dispersão é autocórica (Silva Junior e Pereira 2009).

\section{Metodologia}

Pesquisa de natureza quantitativa, experimental realizada no Laboratório de Produção Vegetal da Universidade Federal Rural da Amazônia no município de Parauapebas - Pará. Sementes de B. rufa foram coletadas, na Floresta Nacional de Carajás sob autorização do ICMBIO. Após a coleta as sementes foram armazenadas e transportadas ao laboratório, onde foram submetidas às análises.

A análise biométrica (comprimento, largura, espessura), foi realizada em um lote de 100 sementes escolhidas ao acaso de uma amostra composta sendo a mensuração feita com o uso de paquímetro digital. O peso de mil sementes foi realizado com dez sub-amostras de 100 sementes, as quais tiveram sua biomassa fresca pesada em balança de precisão e umidade determinada em quatro sub-amostras de $1 \mathrm{~g}$ de sementes submetidas ao método da estufa a $105 \pm 3^{\circ} \mathrm{C}$ durante 24 horas de acordo com a Regra de análise de sementes (BRASIL, 2009).

A curva de embebição foi realizada com a pesagem sistemática utilizando-se 10 subamostras de uma semente, que foram imersas em um Becker de $50 \mathrm{ml}$, contendo água destilada. $\mathrm{O}$ nível de absorção foi medido a cada hora entre 0 e 82 horas. Ao final de cada período as sementes foram pesadas. A média de absorção de água das 10 repetições foi calculada o teor de água absorvida em cada tempo pela seguinte expressão:

$$
\text { Absorção de água }(\%)=\left(\frac{P f-P i}{P i}\right) \times 100
$$

Onde, $P i$ : peso inicial das sementes e $P f$ : peso final das sementes em cada tempo

Para análise de superação de dormência foram separadas vinte amostras com cinquenta sementes cada, em que cada quatro destas foram submetidas aos seguintes métodos de superação de dormência: testemunha (sem superação de dormência); imersão em água em teperatura ambiente; imersão em água a $60{ }^{\circ} \mathrm{C}$; imersão em água a $90{ }^{\circ} \mathrm{C}$ e escarificação em ácido sulfúrico por 5 minutos em solução 98\%. As sementes foram postas sobre papel germiteste em gerbox plásticas e 
em uma câmara de germinação (BOD) na temperatura de $25^{\circ} \mathrm{C}$ e fotoperíodo de $12 \mathrm{~h}$ de luz e $12 \mathrm{~h}$ de escuro. Diariamente foi realizada rega e contabilizada a quantidade de sementes germinadas até o décimo segundo dia após a implantação do teste. Para a determinação do índice de velocidade de germinação, foi multiplicado o número de plântulas emergidas no dia pelo inverso do número de dias transcorridos da data de semeadura, fazendo-se, em seguida, o somatório dos valores obtidos.

Utilizou-se delineamento experimental inteiramente casualizado. Os dados de superação de dormência e biometria foram submetidos a análise de variância pelo teste $\mathrm{F}$, e para comparação das médias o teste Tukey $(\mathrm{p}<0,01)$. Para embebição foi realizada análise de regressão que melhor se ajustasse ao fenômeno trifásico de embebição das sementes.

\section{Resultados e Discussões}

As sementes possuem dimensões médias de: 6,63 $\mathrm{mm}$ de comprimento, 5,45 $\mathrm{mm}$ de largura e 2,46 mm de espessura (Tabela 1). Vaz \& Tozzi (2003) observaram que as dimensões de comprimento e largura também para a espécie B. rufa foram de 11 e $10 \mathrm{~mm}$ respectivamente, diferindo dos valores obtidos nesse experimento. Esse fato pode ter ocorrido devido as plantas ocorrentes no interior da FLONA de Carajás estarem em ambiente de solo com menor teor de nutrientes e elevada concentração de Ferro, características marcantes dessa região.

Tabela 1: Médias de comprimento, largura, espessura, peso de mil sementes e grau de umidade de Bauhinia rufa.

\begin{tabular}{|c|c|c|c|c|}
\hline Variável & Média (mm) & Mínimo (mm) & Máximo (mm) & Coeficiente de variação (\%) \\
\hline Comprimento & 6,63 & 5,4 & 8,65 & 9,85 \\
\hline Largura & 5,45 & 10,47 & 4,07 & 10,47 \\
\hline Espessura & 2,46 & 13,14 & 1,77 & 13,14 \\
\hline Peso de mil sementes (g) & 70,55 & - & - & - \\
\hline Grau de umidade (\%) & 16,43 & - & - & - \\
\hline
\end{tabular}

Observou-se que a massa média por semente foi $0,062 \mathrm{~g}$, onde se estima uma quantidade de 16.130 sementes $\mathrm{Kg}^{-1}$ com grau de umidade de $16,43 \%$ (Tabela 1). A informação é de grande valia para calibrar a necessidade de sementes a ser utilizadas para densidade de plantas por área.

Observa-se o padrão trifásico de absorção de água nas sementes (Figura 1) com rápido aumento no teor de umidade das sementes até $31 \mathrm{~h}$, sendo esta fase referente a fase I, a qual corresponde a um efeito físico na absorção de água. Zuchi et al (2012), relatam que em sementes cotiledonares essa fase leva em média $2 \mathrm{~h}$, um valor bem inferior ao encontrado neste experimento, e possivelmente provocado por barreira física a entrada de água na semente. 
Figura 1: Padrão de embebição de sementes de Bauhinia rufa (Fonte própria).

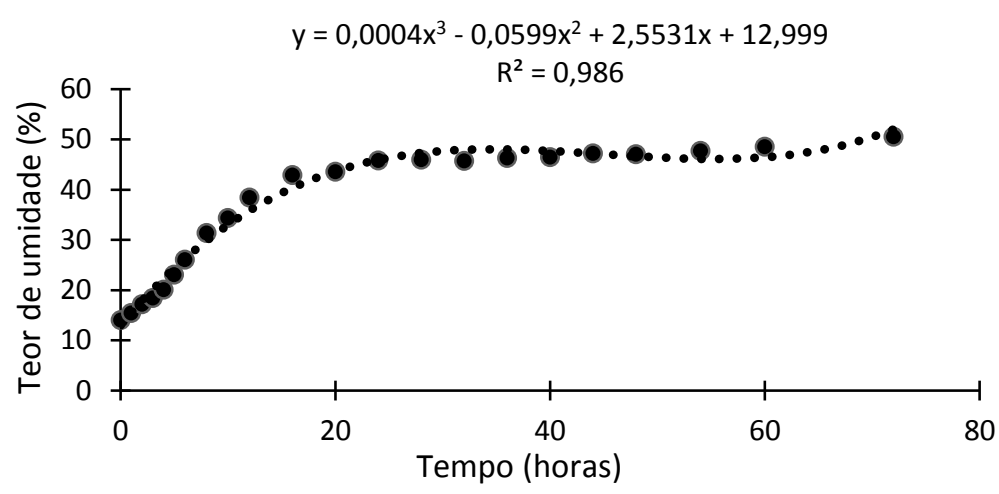

A fase II correspondeu a estabilização da umidade da semente entre 31 e 69 h (Figura 1). Nessa fase é onde ocorre intensa atividade metabólica. A fase III se caracteriza pela protrusão da radícula e retomada de crescimento e absorção de água necessária ao crescimento embrionário.

O tratamento com imersão em ácido sulfúrico foi o que proporcionou maior percentual de germinação e maior índice de velocidade de germinação (Tabela 2), os demais tratamentos não apresentaram diferença. O menor percentual de umidade na fase II da embebição e melhor superação de dormência com ácido sulfúrico indica que o tegumento pode ser uma barreira a absorção de água e gases, interferindo de maneira significativa a germinação das sementes de Bauhinia rufa. Alderete-Chávez et al. (2011) obtiveram resultado de $42 \%$ a $57 \%$ de germinação utilizando ácido sulfúrico em sementes de B. divircata e Smiderle \& Luz (2010), também conseguiram resultados significativos com tratamento de sementes de $B$. angulata em ácido sulfúrico.

Tabela 2: Porcentagem de germinação e índice de velocidade de germinação (IVG) de Bauhinia rufa em diferentes tratamentos para superação de dormência. Letras iguais na coluna não diferem entre si a $1 \%$ de probabilidade pelo Teste

\begin{tabular}{|c|c|c|}
\hline Tratamento Tukey. & Germinação $(\%)$ & IVG \\
\hline Testemunha & $18,00 \mathrm{~b}$ & $2,87 \mathrm{~b}$ \\
\hline Imersão em água em teperatura ambiente & $17,33 \mathrm{~b}$ & $3,35 \mathrm{~b}$ \\
\hline Imersão em água a $60^{\circ} \mathrm{C}$ & $14,67 \mathrm{~b}$ & $2,36 \mathrm{~b}$ \\
\hline Imersão em água a $90^{\circ} \mathrm{C}$ & $10,67 \mathrm{~b}$ & $2,35 \mathrm{~b}$ \\
\hline Escarificação em ácido sulfúrico & $58,67 \mathrm{a}$ & $6,73 \mathrm{a}$ \\
\hline
\end{tabular}

\section{Conclusões}

Sementes de Bauhinia rufa coletadas na FLONA Carajás apresentam dimensões menores que a média de outras regiões. O número de sementes por kg é 16.130 sementes. Há padrão trifásico de absorção de água e o tratamento com ácido sulfúrico deve ser usado para incrementar a 
germinação de sementes de B. rufa.

\section{Referências}

ALDERETE-CHAVEZ, A.; CRUZ-LANDERO, N， DE LA; GUERRA-SANTOS， J. J.; GUEVARA, E.; GELABERT, R.; CRUZ-MAGANA, L. R. DE LA; NUNES LA RARA, E.; (2011). Promotion of germination of Bauhinia divaricata L. seeds by effects of chemical scarification. Res. J. Seed Sci., 4(1) : 51-57.

ALVES, E.U.; BRUNO, R. de L.A.; OLIVEIRA, A.P. de; ALVES, A.U.; ALVES, A.U.; PAULA, R.C. de. Influência do tamanho e da procedência de sementes Mimosa caesalpiniifolia Benth. Sobre a germinação e vigor. Rev. Árvore, vol.29, n.6, pp. 877-885. 2005

BICHUETTE, M. E.; VARANDA. E. M.; BAROSELA, J. R. Effects of ester fractions from leaf epicuticular waxes of Bauhinia rufa (Steud.) Bong. And Stryphnodendron adstringens (Mart.) Coville from cerrado on the aphid Rhopalosiphum maidis (Fitch.). Rev. brasil. Bot., v.21, n.1, p.101-104, 1998.

BRASIL. Ministério da Agricultura e Reforma Agrária. Regras para análises de sementes. Brasília: SNDA/ DNDV/CLAV. 2009. 399 p.

CRUZ, E.D.; MARTINS, F. de O.; CARVALHO, J.E.U. de. Biometria de frutos e sementes e germinação de jatobá-curuba (Hymenaea intermedia Ducke, Leguminosae - Caesalpinioideae). Revista Brasileira de Botânica. 2001, vol.24, n.2, pp. 161-165.

HOFFMAN, J. Avaliação mediadora: uma prática em construção da pré-escola à universidade. Porto Alegre: Mediação, 2001.

LIMA, K. S. Compreendendo as concepções de avaliação de professores de física através da teoria dos construtos pessoais. Recife, 2008. 163 p. Dissertação (Ensino das Ciências). Departamento de Educação, UFRPE, 2008.

NARDI, R.; CORTELLA, B. S. C. Formação de professores de Física: das intenções legais ao discurso dos formadores. In: XVI Simpósio Nacional de Ensino de Física, 2005, Rio de Janeiro. Caderno de Resumos. São Paulo - SP: Sociedade Brasileira de Física, 2005. v. 1. p. 175-175, 2005.

SILVA JUNIOR, M.C. \& PEREIRA B.A.S. 2009. Mais 100 árvores do Cerrado. Matas de Galeria. Guia de Campo. W. Rizzo, ed.. Rede de Sementes do Cerrado.

SMIDERLE, O. J. \& LUZ, F. J. DE F. Superação da dormência em sementes de pata-de-vaca (Bauhinia angulata Vell).Revista Agro@mbiente On-line, Boa Vista, v. 4, n. 2, p. 80-85, 2010. Disponivel em: <http://www.agroambiente.ufrr.br>. Acesso em 20 out, 2014.

VAZ, A.M.S. da F. \& TOZZI, A.M.G.A. Bauhinia ser. Cansenia (Leguminosae: Caesalpinioideae) no Brasil. Rodriguésia, v. 54, n. 83, p. 55-143, 2003. 
ZUCHI, J.; PANOZZO, L. E.; HEBERLE, E.; ARAUJO, E. F.Curva de embebição e condutividade elétrica de sementes de mamona classificadas por tamanho. Revista Brasileira de Sementes, vol. 34, no 3 p. $504-509,2012$.

\section{Agradecimentos}

A VALE pelo financiamento do projeto e concessão de bolsas de iniciação científica. 